\title{
A Taguchi approach on optimal process control parameters for HDPE pipe extrusion process
}

\author{
G. V. S. S. Sharma ${ }^{1}$ (D) R. Umamaheswara $\operatorname{Rao}^{1} \cdot$ P. Srinivasa Rao ${ }^{2}$
}

Received: 12 February 2014/ Accepted: 11 December 2016/Published online: 24 December 2016

(c) The Author(s) 2016. This article is published with open access at Springerlink.com

\begin{abstract}
High-density polyethylene (HDPE) pipes find versatile applicability for transportation of water, sewage and slurry from one place to another. Hence, these pipes undergo tremendous pressure by the fluid carried. The present work entails the optimization of the withstanding pressure of the HDPE pipes using Taguchi technique. The traditional heuristic methodology stresses on a trial and error approach and relies heavily upon the accumulated experience of the process engineers for determining the optimal process control parameters. This results in setting up of less-than-optimal values. Hence, there arouse a necessity to determine optimal process control parameters for the pipe extrusion process, which can ensure robust pipe quality and process reliability. In the proposed optimization strategy, the design of experiments (DoE) are conducted wherein different control parameter combinations are analyzed by considering multiple setting levels of each control parameter. The concept of signal-to-noise ratio ( $S / N$ ratio) is applied and ultimately optimum values of process control parameters are obtained as: pushing zone temperature of $166{ }^{\circ} \mathrm{C}$, Dimmer speed at $08 \mathrm{rpm}$, and Die head temperature to be $192{ }^{\circ} \mathrm{C}$. Confirmation experimental run is also conducted to verify the analysis and research result and values proved to be in synchronization with the main experimental findings and the withstanding pressure showed a significant improvement from 0.60 to $1.004 \mathrm{Mpa}$.
\end{abstract}

G. V. S. S. Sharma

sarma.gvss@gmail.com

1 Department of Mechanical Engineering, GMR Institute of Technology, GMR Nagar, Rajam 532127, India

2 Department of Mechanical Engineering, Centurion University, Parlakhemundi, Odhisa 761211, India
Keywords Design of experiments (DOE) - Analysis of variance $($ ANOVA) $\cdot$ Signal to noise $(S / N)$ ratio $\cdot$ Taguchi approach

\section{Introduction}

The manufacture of HDPE pipes of $32 \mathrm{~mm}$ outer diameter involves an extrusion process for extruding a hollow pipe using blow molding technique. The elements required for extrusion process are the extruding machine setup and PolyEthylene (PE) granules. The selected material for the pipe (PE granules) is first heated in the mixer machine. After attaining the required temperature, it is manually fed into the extruder machine through a feeder. Here, the material enters into the long barrel of the machine where the material is fed all through the process through the feeding zone, melts in the melting zone and is pushed into the die head in the pushing zone. Here, the barrel is divided into three zones to maintain equal material flow rate throughout the process. For this purpose, a rotating screw is fixed inside the barrel (which would be almost the size of the barrel). This screw pushes the material from the feeder to the die head. The die head is fixed, based on the diameter of the pipe required. At this die head, pressurized air is sent in between the material for attaining hollow shape. The pipe coming out of the die head is cooled using cooling water supply for the solidification purpose. Proper cooling temperature should be maintained for the solidification and smooth finish of the pipe at the die head. The pipe coming out of die head is first sent into the cooling tank and then it is pulled by the take-off machine. The speed of the take-off machine is set based on the required pipe thickness. This pipe will be further sent for pressure testing to test the withstanding pressure. HDPE plastic pipes are mainly used 
for transportation of water from one place to another place. Hence, these pipes undergo tremendous pressure by water. Higher withstanding pressure is supposed to result in a better condition of the pipe. Therefore, the withstanding pressure should be set the higher the better.

The pressure test was carried out not earlier than $24 \mathrm{~h}$ after the pipes have been manufactured. The test specimen consisting of pipe having free length between the end fittings equal to ten times the outside diameter, but not less than $250 \mathrm{~mm}$ and not greater than $750 \mathrm{~mm}$, has been taken for testing from each pipe to be tested. The apparatus consisting of equipment permitted the application of a controlled internal hydraulic pressure to the specimens which are immersed in a thermostatically controlled water bath.

The pressure testing procedure was performed in three steps as follows:

Step 1: The pipes were fitted with the locking plugs at both ends in such a way that the axial forces coming from the internal pressure are transmitted to the pipe. The pipe was remained free to move in longitudinal direction.

Step 2: Through a closable opening in one of the locking plugs, the pipe was filled with water at ambient temperature. It was then put in a water bath at the test temperature of $80{ }^{\circ} \mathrm{C}$ and kept in the bath for minimum $1 \mathrm{~h}$ to adjust the temperature.

Step 3: The pressure in the pipe was then increased to the test pressure $(p=3.8 \mathrm{Mpa})$ gradually and without shock, preferably within $10-30 \mathrm{~s}$ in the bath.

After the above test procedure, the pipe samples were inspected not to show signs of localized swelling or leakage and burst during the prescribed test duration. If the test showed failure within a distance equivalent to the length of end cap from the end, then it was discarded and the test repeated.

Figure 1 shows the process flow chart of the HDPE pipe manufacturing process. Figure 2 shows the extruding machine setup with die head and Fig. 3 shows the extruded HDPE pipes. Figure 4 depicts the Dimmer speed regulator and Fig. 5 illustrates the panel board showing different

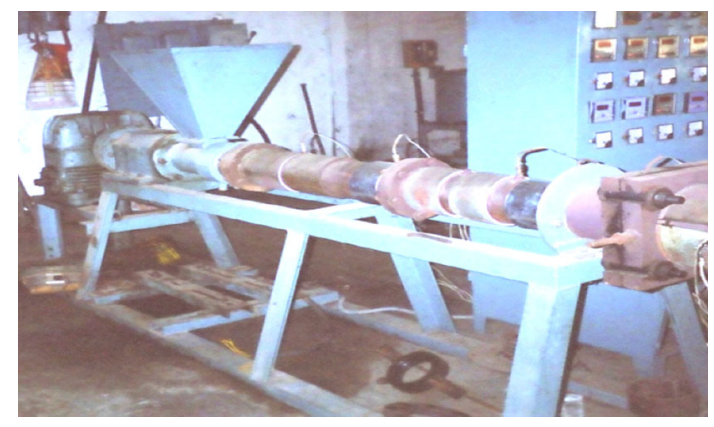

Fig. 2 Extruding machine with die head

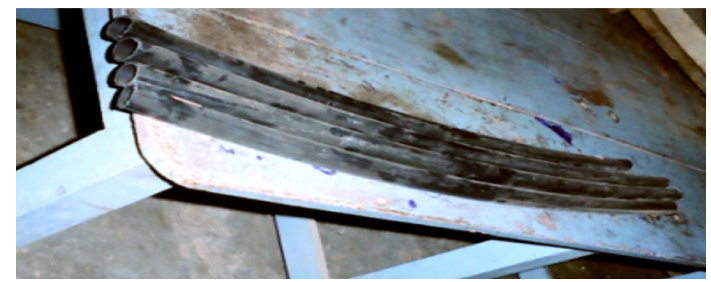

Fig. 3 The extruded HDPE pipes

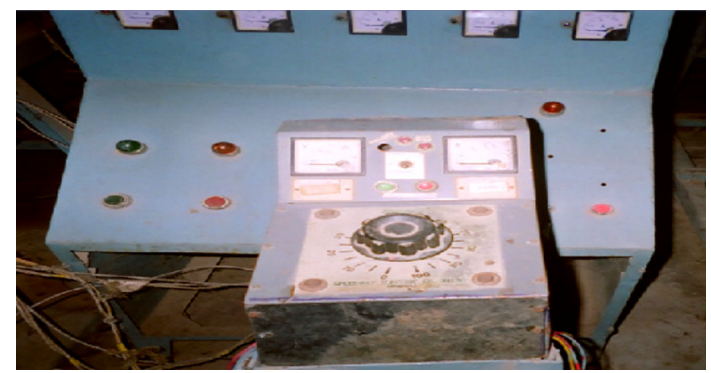

Fig. 4 Dimmer speed regulator

zone temperatures. Figure 6 shows the photograph of hydrostatic pressure testing machine with the end plugs arrangements, used for testing the withstanding pressure of the HDPE extruded pipes.

The key product characteristic of concern is the withstanding pressure of the pipe. The process control parameters influencing the withstanding pressure of the pipes are: the feeding zone temperature, melting zone temperature, pushing zone temperature, dimmer speed and die head temperature. These are the factors which mainly govern the withstanding pressure to improve the pipe quality. Among

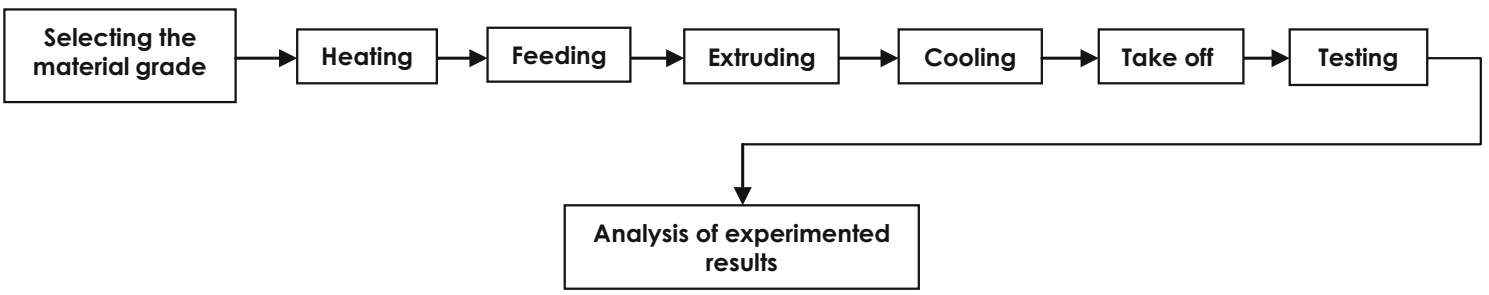

Fig. 1 Process flow chart of the HDPE pipe manufacturing process 


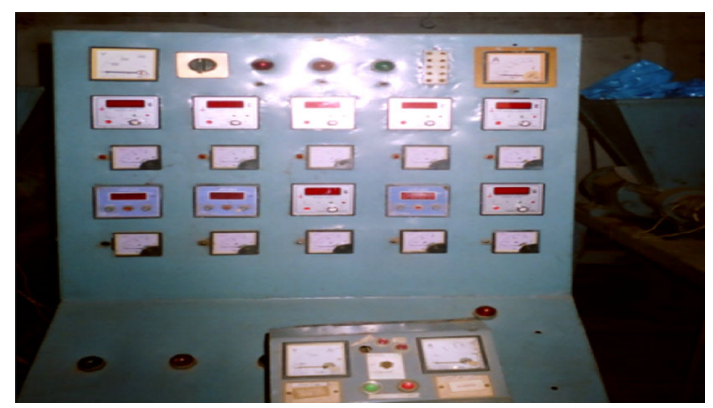

Fig. 5 Panel board showing different zone temperatures

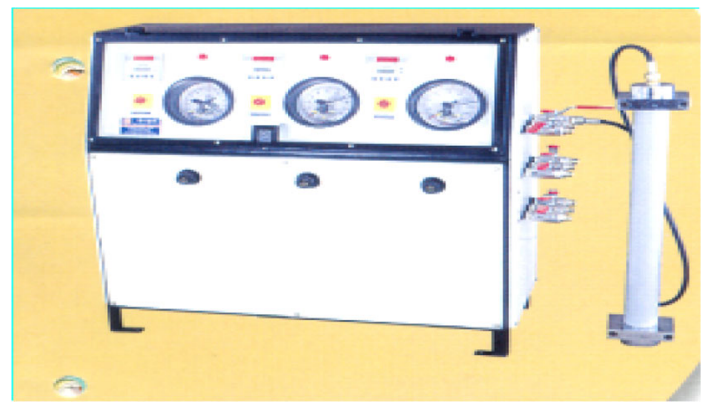

Fig. 6 Hydrostatic pressure testing machine

the enlisted process control parameters, it is necessary to identify the dominant factors, reducing the variables and determining the optimal process control variable values to promote the efficiency of the extrusion manufacturing process.

In this research, the method of experimental design and selection of the related factors to implement the experiment of the extrusion process are applied. The observations (response value) on the experiments are analyzed by the concept of signal-to-noise ratios $(S / N)$ taken from different levels of the related factors. Moreover, the optimal combination of control parameters is recognized to gain the optimized pipe quality and reduce variability. Finally, confirmation experiments using the optimal combination of control parameters are implemented. The confirmation experiment confirms the results of the main experiment.

\section{Literature review}

This section presents a comprehensive review report of the literature surveyed in the areas of Taguchi method of design of experiments and enlists the improvements achieved through the said process.

$\mathrm{Yu}$ et al. (2004) determined the optimal die gap programming of extrusion blow molding processes that establish a back propagation network using a Taguchi's experimental array to predict the relationship between design variables and responses. Lakshminarayanan and
Balasubramanian (2008) applied the Taguchi approach and determined the optimal value of tensile strength of friction stir-welded RDE-40 aluminum alloy as $303 \mathrm{MPa}$. Through the Taguchi parametric design approach, the optimum levels of parameters were determined and the results were confirmed by further experiments. Parameswara Rao and Sarcar (2009) studied the influence of optimal parameters of wire cut EDM on cutting speed, surface roughness, spark gap and material removal rate of brass workpiece. This study was useful in finding cutting time for any size of job and to set parameters namely discharge current, voltage at rated wire speed and tension, for required surface finish with high accuracy of cutting. Kim and Lee (2009) once again applied the Taguchi method to determine the hybrid welding conditions of aluminum alloy (AA5052-H32). By employing Taguchi method, they determined the optimal process parameters associated with hybrid welding of aluminum alloy. Results of tensile testing corresponding to orthogonal array were used to compute signal-to-noise ratios for optimal combination of parameters. The most crucial hybrid welding parameter determined by ANOVA was the weld direction. Chen et al. (2009) identified that the critical to quality characteristic identified was the roundness of holes cut by a plasma machine. They conducted the design of experiments with a total of 36 experiments in which the optimal setting combination was identified as $93 \mathrm{in} / \mathrm{min}$ for feed rate, $100 \mathrm{~V}$ for voltage and 63 A for amperage. Prashantha et al. (2009) in their research found that the addition of $2 \mathrm{wt} \%$ of carbon nanotubes into polypropylene (PP) significantly reduced the shrinkage and warpage of injection-moulded parts up to $48 \%$. The method employed was the Taguchi approach to study the effects of process parameters on the warpage and shrinkage of injection-moulded parts. Kamaruddin et al. (2010) evaluated the performance of plastic $(75 \%$ polypropylene and $25 \%$ low-density polyethylene LPDE) trays in terms of its shrinkage behavior. An orthogonal array (OA), main effect, signal-to-noise $(S / N)$ ratio and analysis of variance (ANOVA) are employed to analyze the effect of injection molding parameters on the shrinkage behavior of the product. The optimum total shrinkage is found to be $0.1521 \mathrm{~cm}$. Using Taguchi method for design of experiment (DOE), other significant effects such as

Table 1 The different process parameters and their levels

\begin{tabular}{llcc}
\hline S. no. & Parameters & Level 1 & Level 2 \\
\hline 1 & Feeding zone temperature & 135 & 148 \\
2 & Melting zone temperature & 175 & 178 \\
3 & Pushing zone temperature & 155 & 160 \\
4 & Dimmer speed & 16 & 20 \\
5 & Die head temperature & 181 & 190 \\
\hline
\end{tabular}


Table 2 Taguchi standard orthogonal array $\mathrm{OA}_{32}\left(2^{31}\right)$

\begin{tabular}{|c|c|c|c|c|c|c|c|c|c|c|c|c|c|c|c|c|}
\hline & 1 & 2 & 3 & 4 & 5 & 6 & 7 & 8 & 9 & 10 & 11 & & 12 & 13 & 14 & 15 \\
\hline 1 & 1 & 1 & 1 & 1 & 1 & 1 & 1 & 1 & 1 & 1 & 1 & & 1 & 1 & 1 & 1 \\
\hline 2 & 1 & 1 & 1 & 1 & 1 & 1 & 1 & 1 & 1 & 1 & 1 & & 1 & 1 & 1 & 1 \\
\hline 3 & 1 & 1 & 1 & 1 & 1 & 1 & 1 & 2 & 2 & 2 & 2 & & 2 & 2 & 2 & 2 \\
\hline 4 & 1 & 1 & 1 & 1 & 1 & 1 & 1 & 2 & 2 & 2 & 2 & & 2 & 2 & 2 & 2 \\
\hline 5 & 1 & 1 & 1 & 2 & 2 & 2 & 2 & 1 & 1 & 1 & 1 & & 2 & 2 & 2 & 2 \\
\hline 6 & 1 & 1 & 1 & 2 & 2 & 2 & 2 & 1 & 1 & 1 & 1 & & 2 & 2 & 2 & 2 \\
\hline 7 & 1 & 1 & 1 & 2 & 2 & 2 & 2 & 2 & 2 & 2 & 2 & & 1 & 1 & 1 & 1 \\
\hline 8 & 1 & 1 & 1 & 2 & 2 & 2 & 2 & 2 & 2 & 2 & 2 & & 1 & 1 & 1 & 1 \\
\hline 9 & 1 & 2 & 2 & 1 & 1 & 2 & 2 & 1 & 1 & 2 & 2 & & 1 & 1 & 2 & 2 \\
\hline 10 & 1 & 2 & 2 & 1 & 1 & 2 & 2 & 1 & 1 & 2 & 2 & & 2 & 2 & 1 & 1 \\
\hline 11 & 1 & 2 & 2 & 1 & 1 & 2 & 2 & 2 & 2 & 1 & 1 & & 2 & 2 & 1 & 1 \\
\hline 12 & 1 & 2 & 2 & 1 & 1 & 2 & 2 & 2 & 2 & 1 & 1 & & 2 & 2 & 1 & 1 \\
\hline 13 & 1 & 2 & 2 & 2 & 2 & 1 & 1 & 1 & 1 & 2 & 2 & & 2 & 2 & 1 & 1 \\
\hline 14 & 1 & 2 & 2 & 2 & 2 & 1 & 1 & 1 & 1 & 2 & 2 & & 2 & 2 & 1 & 1 \\
\hline 15 & 1 & 2 & 2 & 2 & 2 & 1 & 1 & 2 & 2 & 1 & 1 & & 1 & 1 & 2 & 2 \\
\hline 16 & 1 & 2 & 2 & 2 & 2 & 1 & 1 & 2 & 2 & 1 & 1 & & 1 & 1 & 2 & 2 \\
\hline 17 & 2 & 1 & 2 & 1 & 2 & 1 & 2 & 1 & 2 & 1 & 2 & & 1 & 2 & 1 & 2 \\
\hline 18 & 2 & 1 & 2 & 1 & 2 & 1 & 2 & 1 & 2 & 1 & 2 & & 1 & 2 & 1 & 2 \\
\hline 19 & 2 & 1 & 2 & 1 & 2 & 1 & 2 & 2 & 1 & 2 & 1 & & 2 & 1 & 2 & 1 \\
\hline 20 & 2 & 1 & 2 & 1 & 2 & 1 & 2 & 2 & 1 & 2 & 1 & & 2 & 1 & 2 & 1 \\
\hline 21 & 2 & 1 & 2 & 2 & 1 & 2 & 1 & 1 & 2 & 1 & 2 & & 2 & 1 & 2 & 1 \\
\hline 22 & 2 & 1 & 2 & 2 & 1 & 2 & 1 & 1 & 2 & 1 & 2 & & 2 & 1 & 2 & 1 \\
\hline 23 & 2 & 1 & 2 & 2 & 1 & 2 & 1 & 2 & 1 & 2 & 1 & & 1 & 2 & 1 & 2 \\
\hline 24 & 2 & 1 & 2 & 2 & 1 & 2 & 1 & 2 & 1 & 2 & 1 & & 1 & 2 & 1 & 2 \\
\hline 25 & 2 & 2 & 1 & 1 & 2 & 2 & 1 & 1 & 2 & 2 & 1 & & 1 & 2 & 2 & 1 \\
\hline 26 & 2 & 2 & 1 & 1 & 2 & 2 & 1 & 1 & 2 & 2 & 1 & & 1 & 2 & 2 & 1 \\
\hline 27 & 2 & 2 & 1 & 1 & 2 & 2 & 1 & 2 & 1 & 1 & 2 & & 2 & 1 & 1 & 2 \\
\hline 28 & 2 & 2 & 1 & 1 & 2 & 2 & 1 & 2 & 1 & 1 & 2 & & 2 & 1 & 1 & 2 \\
\hline 29 & 2 & 2 & 1 & 2 & 1 & 1 & 2 & 1 & 2 & 2 & 1 & & 2 & 1 & 1 & 2 \\
\hline 30 & 2 & 2 & 1 & 2 & 1 & 1 & 2 & 1 & 2 & 2 & 1 & & 2 & 1 & 1 & 2 \\
\hline 31 & 2 & 2 & 1 & 2 & 1 & 1 & 2 & 2 & 1 & 1 & 2 & & 1 & 2 & 2 & 1 \\
\hline \multirow[t]{2}{*}{32} & 2 & 2 & 1 & 2 & 1 & 1 & 2 & 2 & 1 & 1 & 2 & & 1 & 2 & 2 & 1 \\
\hline & 16 & 17 & 18 & 19 & 20 & 21 & 22 & 23 & 24 & 25 & 26 & 27 & 28 & 29 & 30 & 31 \\
\hline 1 & 1 & 1 & 1 & 1 & 1 & 1 & 1 & 1 & 1 & 1 & 1 & 1 & 1 & 1 & 1 & 1 \\
\hline 2 & 2 & 2 & 2 & 2 & 2 & 2 & 2 & 2 & 2 & 2 & 2 & 2 & 2 & 2 & 2 & 2 \\
\hline 3 & 1 & 1 & 1 & 1 & 1 & 1 & 1 & 1 & 2 & 2 & 2 & 2 & 2 & 2 & 2 & 2 \\
\hline 4 & 2 & 2 & 2 & 2 & 2 & 2 & 2 & 2 & 1 & 1 & 1 & 1 & 1 & 1 & 1 & 1 \\
\hline 5 & 1 & 1 & 1 & 1 & 2 & 2 & 2 & 2 & 1 & 1 & 1 & 1 & 2 & 2 & 2 & 2 \\
\hline 6 & 2 & 2 & 2 & 2 & 1 & 1 & 1 & 1 & 2 & 2 & 2 & 2 & 1 & 1 & 1 & 1 \\
\hline 7 & 1 & 1 & 1 & 1 & 2 & 2 & 2 & 2 & 2 & 2 & 2 & 2 & 1 & 1 & 1 & 1 \\
\hline 8 & 2 & 2 & 2 & 2 & 1 & 1 & 1 & 1 & 1 & 1 & 1 & 1 & 2 & 2 & 2 & 2 \\
\hline 9 & 1 & 1 & 2 & 2 & 1 & 1 & 2 & 2 & 1 & 1 & 2 & 2 & 1 & 1 & 2 & 2 \\
\hline 10 & 2 & 2 & 1 & 1 & 2 & 2 & 1 & 1 & 2 & 2 & 1 & 1 & 2 & 2 & 1 & 1 \\
\hline 11 & 1 & 1 & 2 & 2 & 1 & 1 & 2 & 2 & 2 & 2 & 1 & 1 & 2 & 2 & 1 & 1 \\
\hline 12 & 2 & 2 & 1 & 1 & 2 & 2 & 1 & 1 & 1 & 1 & 2 & 2 & 1 & 1 & 2 & 2 \\
\hline 13 & 1 & 1 & 2 & 2 & 2 & 2 & 1 & 1 & 1 & 1 & 2 & 2 & 2 & 2 & 1 & 1 \\
\hline 14 & 2 & 2 & 1 & 1 & 1 & 1 & 2 & 2 & 2 & 2 & 1 & 1 & 1 & 1 & 2 & 2 \\
\hline 15 & 1 & 1 & 2 & 2 & 2 & 2 & 1 & 1 & 2 & 2 & 1 & 1 & 1 & 1 & 2 & 2 \\
\hline
\end{tabular}


Table 2 continued

\begin{tabular}{llllllllllllllllll}
\hline & 16 & 17 & 18 & 19 & 20 & 21 & 22 & 23 & 24 & 25 & 26 & 27 & 28 & 29 & 30 & 31 \\
\hline 16 & 2 & 2 & 1 & 1 & 1 & 1 & 2 & 2 & 1 & 1 & 2 & 2 & 2 & 2 & 1 & 1 \\
17 & 1 & 2 & 1 & 2 & 1 & 2 & 1 & 2 & 1 & 2 & 1 & 2 & 1 & 2 & 1 & 2 \\
18 & 2 & 1 & 2 & 1 & 2 & 1 & 2 & 1 & 2 & 1 & 2 & 1 & 2 & 1 & 2 & 1 \\
19 & 1 & 2 & 1 & 2 & 1 & 2 & 1 & 2 & 2 & 1 & 2 & 1 & 2 & 1 & 2 & 1 \\
20 & 2 & 1 & 2 & 1 & 2 & 1 & 2 & 1 & 1 & 2 & 1 & 2 & 1 & 2 & 1 \\
21 & 1 & 2 & 1 & 2 & 2 & 1 & 2 & 1 & 1 & 2 & 1 & 2 & 2 & 1 & 2 \\
22 & 2 & 1 & 2 & 1 & 1 & 2 & 1 & 2 & 2 & 1 & 2 & 1 & 1 & 2 \\
23 & 1 & 2 & 1 & 2 & 2 & 1 & 2 & 1 & 2 & 1 & 2 & 1 & 1 & 2 & 1 \\
24 & 2 & 1 & 2 & 1 & 1 & 2 & 1 & 2 & 1 & 2 & 1 & 2 & 2 & 1 & 2 \\
25 & 1 & 2 & 2 & 1 & 1 & 2 & 2 & 1 & 1 & 2 & 2 & 1 & 1 & 2 & 2 \\
26 & 2 & 1 & 1 & 2 & 2 & 1 & 1 & 2 & 2 & 1 & 1 & 2 & 2 & 1 & 1 \\
27 & 1 & 2 & 2 & 1 & 1 & 2 & 2 & 1 & 2 & 1 & 1 & 2 & 2 & 1 & 1 \\
28 & 2 & 1 & 1 & 2 & 2 & 1 & 1 & 2 & 1 & 2 & 2 & 1 & 1 & 2 & 2 \\
29 & 1 & 2 & 2 & 1 & 2 & 1 & 1 & 2 & 1 & 2 & 2 & 1 & 2 & 1 \\
30 & 2 & 1 & 1 & 2 & 1 & 2 & 2 & 1 & 1 & 2 & 1 & 2 & 1 & 2 & 2 \\
31 & 1 & 2 & 2 & 1 & 2 & 1 & 1 & 2 & 2 & 1 & 1 & 2 & 1 & 2 \\
32 & 2 & 1 & 1 & 2 & 1 & 2 & 2 & 1 & 1 & 2 & 2 & 1 & 2 & 1 \\
\hline
\end{tabular}

interaction among injection molding parameters are also investigated. Zaharudin et al. (2012) employed the Taguchi method for optimizing the manufacturing parameters of friction materials produced by powder metallurgy method. The key quality characteristics identified were hardness, specific gravity, and wear. Taguchi method was used for optimizing the manufacturing parameters, namely molding pressure, molding temperature and molding time, for friction materials. Mehat et al. (2012) identified the shrinkage behavior as one of the crucial problems in plastic moulded gear. On integrating the gray relational analysis and Taguchi method, the shrinkage behavior in tooth thickness, addendum and dedendum circles of moulded gear is investigated via optimization of process parameters. The melt temperature was the prominent parameter followed by packing pressure, cooling time and packing time.

Pareek and Bhamniya (2013) used the Taguchi and ANOVA methods for finding an optimum value of the melting temperature, injection pressure and cooling time for an injection molding process. Lal and Vasudevan (2013) employed the Taguchi method comprising $S / N$ ratio and orthogonal arrays for determining the optimum combinations of the process conditions for shrinkage in molding of low-density polyethylene (LPDE). The results showed that the cooling time was the most effective factor for LPDE followed by refilling pressure and injection pressure was found to be the least effective factor. Mariajayaprakash et al. (2013) found the optimum process parameters of shock absorber process using failure mode and effect analysis and genetic algorithm. Chen et al. (2013) studied on simultaneous optimization of multiple interrelated quality indices, leading to product quality improvement in the field of plastic injection molding. The component under consideration was the thin front cover of a digital camera. The ANOVA methodology was applied to find the significant process parameters that affect the part's quality indices and efficient frontier of the process parameters was found with only a few experiments. Sharma and Srinivasa Rao (2013) implemented the six sigma DMAIC and ANOVA combinational approach for improving the machining process performance of thrust face width grinding of a connecting rod of an internal combustion engine. The cause and effect relationship, FMEA and the ANOVA were finally used for identifying the root cause and improving the sigma levels of the connecting rod machining process.

From the above cited literature, it can be construed that the Taguchi approach is widely employed for finding the optimal processing parameters for many manufacturing processes. Thus, in the present investigation, the Taguchi 
Table 3 Levels of factors in each trial and their corresponding results

\begin{tabular}{|c|c|c|c|c|c|c|c|c|}
\hline Level & $\begin{array}{l}\text { Feeding zone } \\
\text { temperature } \\
\left(2^{0}\right)\end{array}$ & $\begin{array}{l}\text { Melting zone } \\
\text { temperature } \\
\left(2^{1}\right)\end{array}$ & $\begin{array}{l}\text { Pushing zone } \\
\text { temperature } \\
\left(2^{2}\right)\end{array}$ & $\begin{array}{l}\text { Dimmer } \\
\text { speed } \\
\left(2^{3}\right)\end{array}$ & $\begin{array}{l}\text { Die head } \\
\text { temperature } \\
\left(2^{4}\right)\end{array}$ & $\begin{array}{l}\text { Pipe } 1 \\
\text { withstanding } \\
\text { pressure (MPa) }\end{array}$ & $\begin{array}{l}\text { Pipe } 2 \\
\text { withstanding } \\
\text { pressure (MPa) }\end{array}$ & $\begin{array}{l}\text { Pipe } 3 \\
\text { withstanding } \\
\text { pressure }(\mathrm{MPa})\end{array}$ \\
\hline 1 & 135 & 175 & 155 & 16 & 181 & 0.648 & 0.734 & 0.837 \\
\hline 2 & 135 & 175 & 155 & 16 & 190 & 0.620 & 0.745 & 0.790 \\
\hline 3 & 135 & 175 & 155 & 20 & 181 & 0.650 & 0.583 & 0.740 \\
\hline 4 & 135 & 175 & 155 & 20 & 190 & 0.600 & 0.627 & 0.727 \\
\hline 5 & 135 & 175 & 160 & 16 & 181 & 0.689 & 0.757 & 0.846 \\
\hline 6 & 135 & 175 & 160 & 16 & 190 & 0.694 & 0.784 & 0.812 \\
\hline 7 & 135 & 175 & 160 & 20 & 181 & 0.596 & 0.633 & 0.713 \\
\hline 8 & 135 & 175 & 160 & 20 & 190 & 0.656 & 0.723 & 0.816 \\
\hline 9 & 135 & 178 & 155 & 16 & 181 & 0.743 & 0.844 & 0.896 \\
\hline 10 & 135 & 178 & 155 & 16 & 190 & 0.646 & 0.740 & 0.844 \\
\hline 11 & 135 & 178 & 155 & 20 & 181 & 0.543 & 0.569 & 0.660 \\
\hline 12 & 135 & 178 & 155 & 20 & 190 & 0.616 & 0.632 & 0.715 \\
\hline 13 & 135 & 178 & 160 & 16 & 181 & 0.643 & 0.731 & 0.812 \\
\hline 14 & 135 & 178 & 160 & 16 & 190 & 0.739 & 0.812 & 0.846 \\
\hline 15 & 135 & 178 & 160 & 20 & 181 & 0.546 & 0.569 & 0.664 \\
\hline 16 & 135 & 178 & 160 & 20 & 190 & 0.521 & 0.641 & 0.749 \\
\hline 17 & 148 & 175 & 155 & 16 & 181 & 0.769 & 0.841 & 0.849 \\
\hline 18 & 148 & 175 & 155 & 16 & 190 & 0.622 & 0.640 & 0.790 \\
\hline 19 & 148 & 175 & 155 & 20 & 181 & 0.598 & 0.696 & 0.788 \\
\hline 20 & 148 & 175 & 155 & 20 & 190 & 0.556 & 0.573 & 0.660 \\
\hline 21 & 148 & 175 & 160 & 16 & 181 & 0.621 & 0.797 & 0.817 \\
\hline 22 & 148 & 175 & 160 & 16 & 190 & 0.723 & 0.814 & 0.896 \\
\hline 23 & 148 & 175 & 160 & 20 & 181 & 0.566 & 0.573 & 0.667 \\
\hline 24 & 148 & 175 & 160 & 20 & 190 & 0.679 & 0.702 & 0.798 \\
\hline 25 & 148 & 178 & 155 & 16 & 181 & 0.711 & 0.725 & 0.816 \\
\hline 26 & 148 & 178 & 155 & 16 & 190 & 0.616 & 0.687 & 0.743 \\
\hline 27 & 148 & 178 & 155 & 20 & 181 & 0.519 & 0.534 & 0.657 \\
\hline 28 & 148 & 178 & 155 & 20 & 190 & 0.579 & 0.590 & 0.670 \\
\hline 29 & 148 & 178 & 160 & 16 & 181 & 0.618 & 0.759 & 0.814 \\
\hline 30 & 148 & 178 & 160 & 16 & 190 & 0.718 & 0.733 & 0.779 \\
\hline 31 & 148 & 178 & 160 & 20 & 181 & 0.641 & 0.661 & 0.772 \\
\hline 32 & 148 & 178 & 160 & 20 & 190 & 0.596 & 0.617 & 0.699 \\
\hline
\end{tabular}

approach for design of experiments is selected as the primary tool for setting up the optimal control parameters for the manufacturing of high-density poly ethylene (HDPE) pipes through extrusion process.

\section{Experimental design or design of experiments (DoE)}

The design of experiments (DoE) is an efficient procedure for planning experiments, so that the data obtained can be analyzed to yield valid and objective conclusions. DoE begins with determining the objectives of an experiment and selecting the process factors for the study. An experimental design is the laying out of a detailed experimental plan in advance of doing the experiment. Well-chosen experimental designs maximize the amount of "information" that can be obtained for a given amount of experimental effect. In an experiment, the values of one or more process factors are changed to observe the effect; the changes have on one or more response variables (factors). In the present study, the main purpose of the experimental design is to understand the effects of changing the level of the factors to the result of extrusion process, especially focusing on the withstanding pressure of the pipe. 
Table 4 ANOVA table

\begin{tabular}{|c|c|c|c|c|c|}
\hline Source & Df & SS & $\mathrm{Mss}=\mathrm{SS} / \mathrm{Df}$ & $F$-ratio & Theoretical $F$-ratic \\
\hline Feeding zone temperature $(A)$ & 1 & 0.003177 & 0.003177 & 0.758 & 7.88 \\
\hline Melting zone temperature $(B)$ & 1 & 0.0125 & 0.0125 & 2.985 & 7.88 \\
\hline Pushing zone temperature $(C)$ & 1 & 0.0168 & 0.0168 & 8.12 & 7.88 \\
\hline Dimmer speed $(D)$ & 1 & 0.29 & 0.29 & 69.253 & 7.88 \\
\hline Die head temperature $(E)$ & 1 & 0.04887 & 0.04887 & 10.52 & 7.88 \\
\hline$A \times B$ & 1 & 0.00643 & 0.00643 & 1.535 & 7.88 \\
\hline$A \times C$ & 1 & 0.008544 & 0.008544 & 2.040 & 7.88 \\
\hline$B \times C$ & 1 & 0.005745 & 0.005745 & 1.3719 & 7.88 \\
\hline$A \times D$ & 1 & 0.005548 & 0.005548 & 1.324 & 7.88 \\
\hline$B \times D$ & 1 & 0.0121 & 0.0121 & 2.889 & 7.88 \\
\hline$C \times D$ & 1 & 0.005873 & 0.005873 & 1.4025 & 7.88 \\
\hline$A \times E$ & 1 & 0.0104 & 0.0104 & 2.483 & 7.88 \\
\hline$B \times E$ & 1 & 0.00406 & 0.00406 & 1.099 & 7.88 \\
\hline$C \times E$ & 1 & 0.0436 & 0.0436 & 10.411 & 7.88 \\
\hline$D \times E$ & 1 & 0.0159 & 0.0159 & 3.797 & 7.88 \\
\hline$A \times B \times C$ & 1 & 0.0119 & 0.0119 & 2.841 & 7.88 \\
\hline$A \times B \times D$ & 1 & 0.017 & 0.017 & 4.059 & 7.88 \\
\hline$A \times C \times D$ & 1 & 0.004861 & 0.004861 & 1.1608 & 7.88 \\
\hline$B \times C \times D$ & 1 & 0.006876 & 0.006876 & 1.642 & 7.88 \\
\hline$A \times B \times E$ & 1 & 0.004992 & 0.004992 & 1.192 & 7.88 \\
\hline$A \times C \times E$ & 1 & 0.008193 & 0.008193 & 1.956 & 7.88 \\
\hline$B \times C \times E$ & 1 & 0.0196 & 0.0196 & 4.08 & 7.88 \\
\hline$A \times D \times E$ & 1 & 0.005358 & 0.005358 & 1.279 & 7.88 \\
\hline$B \times D \times E$ & 1 & 0.0126 & 0.0126 & 3.008 & 7.88 \\
\hline$C \times D \times E$ & 1 & 0.0106 & 0.0106 & 2.531 & 7.88 \\
\hline$A \times B \times C \times D$ & 1 & 0.005664 & 0.005664 & 1.352 & 7.88 \\
\hline$A \times B \times C \times E$ & 1 & 0.0238 & 0.0238 & 5.683 & 7.88 \\
\hline$A \times B \times D \times E$ & 1 & 0.006859 & 0.006859 & 1.668 & 7.88 \\
\hline$A \times C \times D \times E$ & 1 & 0.004848 & 0.004848 & 1.157 & 7.88 \\
\hline$B \times C \times D \times E$ & 1 & 0.024 & 0.024 & 5.731 & 7.88 \\
\hline$A \times B \times C \times D \times E$ & 1 & 0.00728 & 0.00728 & 0.173 & 7.88 \\
\hline
\end{tabular}

The experimental design or the design of experiments (DoE) involves three phases, namely:

Phase 1: preliminary experiments for determining the significant factors.

Phase 2: finding the optimal values among the significant factors.

Phase 3: conducting the confirmatory experiment.

\section{Phase 1: preliminary experiments for determining the significant factors}

For conducting the experimental design, $32 \mathrm{~mm}$ outer diameter pipe with PE63 grade as raw material is chosen.
The factors taken are feeding zone temperature, melting zone temperature, pushing zone temperature, dimmer speed and die head temperature. The experiments are conducted by fixing two levels as per the basic raw material properties. Table 1 shows the different process parameters (factors) and their levels. The two-level and three-level orthogonal array recommended by Taguchi can be utilized for the study of multi-level factors, and are capable of dealing with any required combination of factor levels. In this way, the special peculiarities of factors under study can be handled and specific experimental demands can be met, simply by following certain factor assignment and analysis techniques strongly recommended by Taguchi. The 
Table 5 Formation of $\mathrm{OA}_{32}\left(8^{6} \times 2\right)$ from $\mathrm{OA}_{32}\left(2^{31}\right)$ by multi-level column creation technique

\begin{tabular}{|c|c|c|c|c|c|c|c|}
\hline Trial & $(1,18,19,30,13)$ & $(2,24,26,29,7)$ & $(4,17,21,27,14)$ & $(3,20,28,23,11)$ & $(16,6,22,15,25)$ & $(3,10,9,5,12)$ & 31 \\
\hline 1 & 1 & 1 & 1 & 1 & 1 & 1 & 1 \\
\hline 2 & 1 & 3 & 6 & 3 & 3 & 4 & 2 \\
\hline 3 & 1 & 8 & 3 & 8 & 8 & 7 & 2 \\
\hline 4 & 1 & 6 & 8 & 6 & 6 & 6 & 1 \\
\hline 5 & 2 & 4 & 2 & 2 & 2 & 3 & 2 \\
\hline 6 & 2 & 2 & 5 & 4 & 4 & 2 & 1 \\
\hline 7 & 2 & 5 & 4 & 7 & 7 & 5 & 1 \\
\hline 8 & 2 & 7 & 7 & 5 & 5 & 8 & 2 \\
\hline 9 & 3 & 1 & 3 & 6 & 6 & 3 & 2 \\
\hline 10 & 3 & 3 & 8 & 8 & 8 & 2 & 1 \\
\hline 11 & 3 & 8 & 1 & 3 & 3 & 5 & 1 \\
\hline 12 & 3 & 6 & 6 & 1 & 1 & 8 & 2 \\
\hline 13 & 4 & 4 & 4 & 5 & 5 & 1 & 1 \\
\hline 14 & 4 & 2 & 7 & 7 & 7 & 4 & 2 \\
\hline 15 & 4 & 5 & 2 & 4 & 4 & 7 & 2 \\
\hline 16 & 4 & 7 & 5 & 2 & 2 & 6 & 1 \\
\hline 17 & 5 & 2 & 4 & 2 & 2 & 6 & 2 \\
\hline 18 & 5 & 4 & 7 & 4 & 4 & 7 & 1 \\
\hline 19 & 5 & 7 & 2 & 7 & 7 & 4 & 1 \\
\hline 20 & 5 & 5 & 5 & 5 & 5 & 1 & 2 \\
\hline 21 & 6 & 3 & 3 & 1 & 1 & 8 & 1 \\
\hline 22 & 6 & 1 & 8 & 3 & 3 & 5 & 2 \\
\hline 23 & 6 & 6 & 1 & 8 & 8 & 2 & 2 \\
\hline 24 & 6 & 8 & 6 & 6 & 6 & 3 & 1 \\
\hline 25 & 7 & 2 & 2 & 5 & 5 & 8 & 1 \\
\hline 26 & 7 & 4 & 5 & 7 & 7 & 5 & 2 \\
\hline 27 & 7 & 7 & 4 & 4 & 4 & 2 & 2 \\
\hline 28 & 7 & 5 & 7 & 2 & 2 & 3 & 1 \\
\hline 29 & 8 & 3 & 1 & 6 & 6 & 6 & 2 \\
\hline 30 & 8 & 1 & 6 & 8 & 8 & 7 & 1 \\
\hline 31 & 8 & 6 & 3 & 3 & 3 & 4 & 1 \\
\hline 32 & 8 & 8 & 8 & 1 & 1 & 1 & 2 \\
\hline
\end{tabular}

experimented results are tabulated according to a standard orthogonal array of $\mathrm{OA}_{32}$ recommended by Taguchi. Table 2 shows the standard orthogonal array recommended to Taguchi. For each experiment, a pipe of $3 \mathrm{~m}$ length has been taken and it is tested for its withstanding pressure. Table 3 shows the level of factors in each trial and their corresponding results. After the pressure testing, ANOVA technique is applied and it has been found that three factors (pushing zone temperature, dimmer speed, die head temperature) among the five factors are significant. Table 4 summarizes the ANOVA procedure.
Phase 2: finding the optimal values among the significant factors

For the three significant factors deduced from ANOVA, an orthogonal array, fixing five levels is developed, using multi-level column creation technique and dummy-level technique. According to this array, again second phase of experiments is conducted and the pipes have been tested. Orthogonality is the ability to extract and separate out the effects of different factors. This property is satisfied if, for example, for each pair of factors, every combination of 
Table 6 Dummy-level technique on the $\mathrm{OA}_{32}\left(8^{6} \times 2\right)$

\begin{tabular}{|c|c|c|c|c|c|c|c|}
\hline Trial & $\begin{array}{l}\text { Pushing zone temperature } \\
\text { (pzt) }\end{array}$ & $\begin{array}{l}\text { Dimmer speed } \\
\text { (Ds) }\end{array}$ & Pzt $\times$ Ds & $\begin{array}{l}\text { Die head temperature } \\
\text { (Dh) }\end{array}$ & $(\mathrm{Pzt}) \times(\mathrm{Dh})$ & (Ds) $\times(\mathrm{Dh})$ & $(\mathrm{Pzt}) \times(\mathrm{Ds}) \times(\mathrm{Dh})$ \\
\hline 1 & 1 & 1 & 1 & 1 & 1 & 1 & 1 \\
\hline 2 & 1 & 3 & $6\left(3^{\prime}\right)$ & $8\left(1^{\prime}\right)$ & 3 & 4 & 2 \\
\hline 3 & 1 & $8\left(1^{\prime}\right)$ & 3 & 3 & $8\left(1^{\prime}\right)$ & $7\left(2^{\prime}\right)$ & 2 \\
\hline 4 & 1 & $6\left(3^{\prime}\right)$ & $8\left(1^{\prime}\right)$ & $6\left(3^{\prime}\right)$ & $6\left(3^{\prime}\right)$ & $6\left(3^{\prime}\right)$ & 1 \\
\hline 5 & 2 & 4 & 2 & 5 & 2 & 3 & 2 \\
\hline 6 & 2 & 2 & 5 & 4 & 4 & 2 & 1 \\
\hline 7 & 2 & 5 & 4 & $7\left(2^{\prime}\right)$ & $7\left(2^{\prime}\right)$ & 5 & 1 \\
\hline 8 & 2 & $7\left(2^{\prime}\right)$ & $7\left(2^{\prime}\right)$ & 2 & 5 & $8\left(1^{\prime}\right)$ & 2 \\
\hline 9 & 3 & 1 & 3 & $8\left(1^{\prime}\right)$ & $6\left(3^{\prime}\right)$ & 3 & 2 \\
\hline 10 & 3 & 3 & $8\left(1^{\prime}\right)$ & 1 & $8\left(1^{\prime}\right)$ & 2 & 1 \\
\hline 11 & 3 & $8\left(1^{\prime}\right)$ & 1 & $6\left(3^{\prime}\right)$ & 3 & 5 & 1 \\
\hline 12 & 3 & $6\left(3^{\prime}\right)$ & $6\left(3^{\prime}\right)$ & 3 & 1 & $8\left(1^{\prime}\right)$ & 2 \\
\hline 13 & 4 & 4 & 4 & 4 & 5 & 1 & 1 \\
\hline 14 & 4 & 2 & $7\left(2^{\prime}\right)$ & 5 & $7\left(2^{\prime}\right)$ & 4 & 2 \\
\hline 15 & 4 & 5 & 2 & 2 & 4 & $7\left(2^{\prime}\right)$ & 2 \\
\hline 16 & 4 & $7\left(2^{\prime}\right)$ & 5 & $7\left(2^{\prime}\right)$ & 2 & $6\left(3^{\prime}\right)$ & 1 \\
\hline 17 & 5 & 2 & 4 & $7\left(2^{\prime}\right)$ & 2 & $6\left(3^{\prime}\right)$ & 2 \\
\hline 18 & 5 & 4 & $7\left(2^{\prime}\right)$ & $7\left(2^{\prime}\right)$ & 4 & $7\left(2^{\prime}\right)$ & 1 \\
\hline 19 & 5 & $7\left(2^{\prime}\right)$ & 2 & 4 & $7\left(2^{\prime}\right)$ & 4 & 1 \\
\hline 20 & 5 & 5 & 5 & 5 & 5 & 1 & 2 \\
\hline 21 & $6\left(3^{\prime}\right)$ & 3 & 3 & $6\left(3^{\prime}\right)$ & 1 & $8\left(1^{\prime}\right)$ & 1 \\
\hline 22 & $6\left(3^{\prime}\right)$ & 1 & $8\left(1^{\prime}\right)$ & 3 & 3 & 5 & 2 \\
\hline 23 & $6\left(3^{\prime}\right)$ & $6\left(3^{\prime}\right)$ & 1 & $8\left(1^{\prime}\right)$ & $8\left(1^{\prime}\right)$ & 2 & 2 \\
\hline 24 & $6\left(3^{\prime}\right)$ & $8\left(1^{\prime}\right)$ & $6\left(3^{\prime}\right)$ & 1 & $6\left(3^{\prime}\right)$ & 3 & 1 \\
\hline 25 & $7\left(2^{\prime}\right)$ & 2 & 2 & $7\left(2^{\prime}\right)$ & 5 & $8\left(1^{\prime}\right)$ & 1 \\
\hline 26 & $7\left(2^{\prime}\right)$ & 4 & 5 & 2 & $7\left(2^{\prime}\right)$ & 5 & 2 \\
\hline 27 & $7\left(2^{\prime}\right)$ & $7\left(2^{\prime}\right)$ & 4 & 5 & 4 & 2 & 2 \\
\hline 28 & $7\left(2^{\prime}\right)$ & 5 & $7\left(2^{\prime}\right)$ & 4 & 2 & 3 & 1 \\
\hline 29 & $8\left(1^{\prime}\right)$ & 3 & 1 & 3 & $6\left(3^{\prime}\right)$ & $6\left(3^{\prime}\right)$ & 2 \\
\hline 30 & $8\left(1^{\prime}\right)$ & 1 & $6\left(3^{\prime}\right)$ & $6\left(3^{\prime}\right)$ & $8\left(1^{\prime}\right)$ & $7\left(2^{\prime}\right)$ & 1 \\
\hline 31 & $8\left(1^{\prime}\right)$ & $6\left(3^{\prime}\right)$ & 3 & 1 & 3 & 4 & 1 \\
\hline 32 & $8\left(1^{\prime}\right)$ & $8\left(1^{\prime}\right)$ & $8\left(1^{\prime}\right)$ & $8\left(1^{\prime}\right)$ & 1 & 1 & 2 \\
\hline
\end{tabular}

factor levels exists and occurs equally often. Orthogonal array is represented by $\left(\mathrm{OA}_{n}\left(m^{k}\right)\right)$, in which ' $m$ ' stands for the number factors, ' $n$ ' stands for the no. of trials or experiments required and ' $k$ ' stands for number of levels. Table 5 shows the formation of $\mathrm{OA}_{32}\left(8^{6} \times 2\right)$ from $\mathrm{OA}_{32}\left(2^{31}\right)$ by multi-level column creation technique. Table 6 shows the formation of $\mathrm{OA}_{32}\left(8^{6} \times 2\right)$ from $\mathrm{OA}_{32}\left(2^{31}\right)$ by dummy-level technique. Table 7 shows the final modified orthogonal array applicable for the second phase of experiments. The final selection of the experimental factor and factor's levels is shown in Table 8. From the modified orthogonal array, the levels of factors in each trial are summarized in Table 9. The withstanding pressure values (MPa) for each one meter pipe are summarized in Table 10.

\section{Phase 3: conducting the confirmatory experiment}

A confirmatory experiment is conducted at optimal process parameters as documented in Table 11.

\section{Results and discussion}

The Phase wise results of the DoE performed are discussed as follows: 
Table 7 Modified orthogonal array

\begin{tabular}{|c|c|c|c|c|c|c|c|}
\hline Factor/trial & 1 & 2 & 3 & 4 & 5 & 6 & 7 \\
\hline 1 & 1 & 1 & 1 & 1 & 1 & 1 & 1 \\
\hline 2 & 1 & 3 & 3 & 1 & 3 & 4 & 2 \\
\hline 3 & 1 & 1 & 3 & 3 & 1 & 2 & 2 \\
\hline 4 & 1 & 3 & 1 & 3 & 3 & 3 & 1 \\
\hline 5 & 2 & 4 & 2 & 5 & 2 & 3 & 2 \\
\hline 6 & 2 & 2 & 5 & 4 & 4 & 2 & 1 \\
\hline 7 & 2 & 5 & 4 & 2 & 2 & 5 & 1 \\
\hline 8 & 2 & 2 & 2 & 2 & 5 & 1 & 2 \\
\hline 9 & 3 & 1 & 3 & 1 & 3 & 3 & 2 \\
\hline 10 & 3 & 3 & 1 & 1 & 1 & 2 & 1 \\
\hline 11 & 3 & 1 & 1 & 3 & 3 & 5 & 1 \\
\hline 12 & 3 & 3 & 3 & 3 & 1 & 1 & 2 \\
\hline 13 & 4 & 4 & 4 & 4 & 5 & 1 & 1 \\
\hline 14 & 4 & 2 & 2 & 5 & 2 & 4 & 2 \\
\hline 15 & 4 & 5 & 2 & 2 & 4 & 2 & 2 \\
\hline 16 & 4 & 2 & 5 & 2 & 2 & 3 & 1 \\
\hline 17 & 5 & 2 & 4 & 2 & 2 & 3 & 2 \\
\hline 18 & 5 & 4 & 2 & 2 & 4 & 2 & 1 \\
\hline 19 & 5 & 2 & 2 & 4 & 2 & 4 & 1 \\
\hline 20 & 5 & 5 & 5 & 5 & 5 & 1 & 2 \\
\hline 21 & 3 & 3 & 3 & 3 & 1 & 1 & 1 \\
\hline 22 & 3 & 1 & 1 & 3 & 3 & 5 & 2 \\
\hline 23 & 3 & 3 & 1 & 1 & 1 & 2 & 2 \\
\hline 24 & 3 & 1 & 3 & 1 & 3 & 3 & 1 \\
\hline 25 & 2 & 2 & 2 & 2 & 5 & 1 & 1 \\
\hline 26 & 2 & 4 & 5 & 2 & 2 & 5 & 2 \\
\hline 27 & 2 & 2 & 4 & 5 & 4 & 2 & 2 \\
\hline 28 & 2 & 5 & 2 & 4 & 2 & 3 & 1 \\
\hline 29 & 1 & 3 & 1 & 3 & 3 & 3 & 2 \\
\hline 30 & 1 & 1 & 3 & 3 & 1 & 2 & 1 \\
\hline 31 & 1 & 3 & 3 & 1 & 3 & 4 & 1 \\
\hline 32 & 1 & 1 & 1 & 1 & 1 & 1 & 2 \\
\hline
\end{tabular}

\section{Results of phase 1: preliminary experiments for determining the significant factors}

After performing the preliminary round of experiments, it has been found that three factors (pushing zone temperature, dimmer speed, die head temperature) are the significant factors among the all five factors, namely feeding zone temperature, melting zone temperature, pushing zone temperature, dimmer speed, and die head temperature as, deduced from the ANOVA results tabulated in Table 4.

\section{Results of phase 2: finding the optimal values among the significant factors}

This research concentrated on parameter design which is formatted by Dr. Taguchi to evaluate signal-to-noise ratios $(S / N)$. All the response values generated from this experiment were converted to $S / N$ ratios and the consequent analysis was conducted using the statistic estimation to estimate $S / N$ ratios under different factors-level combinations. The highest value of $S / N$ ratio would be the optimum factor-level combination, because the product would have the minimum variance with this factor level.

The first step of data analysis is to convert all the observed value of experimental combination into $S / N$ ratios. Since the withstanding pressure of the pipe is the larger the better in these experiments, the $S / N$ ratio should be calculated using the following equation:

$S / N$ ratio $=-10 \log _{10}\left\{\frac{1}{n} \sum y^{-2}\right\}$

One of the main purposes of these experiments is to determine the optimum standard level for each factor. According to the definition of $S / N$ ratio, the higher the $S /$ $N$ ratio the better the result quality would be produced. It is because the lower loss was occurred with the higher value of the $S / N$ ratio. It is also the reason that the higher value of the $S / N$ ratio was chosen in the present work.

Table 12 summarizes the withstanding pressure (WSP) signal-to-noise $(S / N)$ ratios and Figs. 7, 8, 9, 10 and 11 give the corresponding graphical plots of the $S / N$ ratios for various levels.

From $S / N$ ratio graph 1 of Fig. 7, it is deduced that at level 4 the pushing zone temperature at $166^{\circ} \mathrm{C}$ is significant and the greater the $S / N$ ratio, the greater is the significance. From $S / N$ ratio graph 2 of Fig. 8, the dimmer

Table 8 Experimental factors and levels

\begin{tabular}{llll}
\hline Factors level & Pushing zone temperature $(A)$ & Dimmer speed $(B)$ & Die head temperature $(C)$ \\
\hline 1 & 160 & 16 & 190 \\
2 & 162 & 14 & 192 \\
3 & 164 & 12 & 194 \\
4 & 166 & 10 & 196 \\
5 & 170 & 08 & 198 \\
\hline
\end{tabular}


Table 9 Levels of factors in each trial

\begin{tabular}{|c|c|c|c|c|c|c|c|}
\hline Factors/trials & $\begin{array}{l}\text { Pushing zone } \\
\text { temperature }\end{array}$ & $\begin{array}{l}\text { Dimmer } \\
\text { speed }\end{array}$ & $\begin{array}{l}\text { Die head } \\
\text { temperature }\end{array}$ & Factors/trials & $\begin{array}{l}\text { Pushing zone } \\
\text { temperature }\end{array}$ & $\begin{array}{l}\text { Dimmer } \\
\text { speed }\end{array}$ & $\begin{array}{l}\text { Die head } \\
\text { temperature }\end{array}$ \\
\hline 1 & 160 & 16 & 190 & 17 & 170 & 14 & 192 \\
\hline 2 & 160 & 12 & 190 & 18 & 170 & 10 & 192 \\
\hline 3 & 160 & 16 & 194 & 19 & 170 & 14 & 196 \\
\hline 4 & 160 & 12 & 194 & 20 & 170 & 8 & 198 \\
\hline 5 & 162 & 10 & 198 & 21 & 164 & 12 & 194 \\
\hline 6 & 162 & 14 & 196 & 22 & 164 & 16 & 194 \\
\hline 7 & 162 & 8 & 192 & 23 & 164 & 12 & 190 \\
\hline 8 & 162 & 14 & 192 & 24 & 164 & 16 & 190 \\
\hline 9 & 164 & 16 & 190 & 25 & 162 & 14 & 192 \\
\hline 10 & 164 & 12 & 190 & 26 & 162 & 8 & 192 \\
\hline 11 & 164 & 16 & 194 & 27 & 162 & 10 & 198 \\
\hline 12 & 164 & 12 & 194 & 28 & 162 & 14 & 196 \\
\hline 13 & 166 & 10 & 196 & 29 & 160 & 12 & 194 \\
\hline 14 & 166 & 14 & 198 & 30 & 160 & 16 & 194 \\
\hline 15 & 166 & 8 & 192 & 31 & 160 & 12 & 190 \\
\hline 16 & 166 & 14 & 192 & 32 & 160 & 16 & 190 \\
\hline
\end{tabular}

speed at level 5, i.e., $8 \mathrm{rpm}$, is significant and from $S /$ $N$ ratio graph 3 of Fig. 9, die head temperature at level 2, i.e., $192{ }^{\circ} \mathrm{C}$, is significant. From $S / N$ ratio graph 4 of Fig. 10, the interactions between pushing zone temperature at $166{ }^{\circ} \mathrm{C}$ and dimmer speed at $8 \mathrm{rpm}$ are significant. From graph 5 of Fig. 11, the interaction between pushing zone temperature at $166{ }^{\circ} \mathrm{C}$ and die head temperature at $192{ }^{\circ} \mathrm{C}$ is significant.

\section{Results of phase 3: conducting the confirmatory experiment}

Confirmatory experiments are conducted on different workpieces with the above-obtained optimum conditions. From the confirmatory experiments, the withstanding pressure values are observed to be more than those obtained in the series of experiments done earlier. The withstanding pressure had improved significantly from the initial values of $0.60-1.004 \mathrm{Mpa}$, as deduced from confirmatory experiment results tabulated in Table 13.

\section{Conclusion}

There are five controllable factors (process parameters) and each of them consists of two levels in these experiments of extrusion process initially. Therefore, $2^{5}=32$ different combinations of the factor's levels were selected and each combination of factor level is separated to do a reduplicate factor experiment. After conducting these experiments, Taguchi's method was used to analyze each response value. The pushing zone temperature, dimmer speed, die head temperature in the extrusion process were correlated significantly to the quality characteristic. 
Table 10 The withstanding pressure values $(\mathrm{MPa})$ for each $1 \mathrm{~m}$ pipe

\begin{tabular}{|c|c|c|c|c|c|c|}
\hline Trial & Position 1 & Position 2 & Position 3 & Position 4 & Position 5 & Position 6 \\
\hline 1 & 0.78 & 0.79 & 0.82 & 0.86 & 0.89 & 0.92 \\
\hline 2 & 0.844 & 0.867 & 0.88 & 0.92 & 0.97 & 0.99 \\
\hline 3 & 0.748 & 0.756 & 0.766 & 0.87 & 0.89 & 0.94 \\
\hline 4 & 0.903 & 0.921 & 0.95 & 0.96 & 0.99 & 1.004 \\
\hline 5 & 0.978 & 0.982 & 0.991 & 1.001 & 1.005 & 1.009 \\
\hline 6 & 0.856 & 0.864 & 0.879 & 0.889 & 0.902 & 0.994 \\
\hline 7 & 1.079 & 1.088 & 1.092 & 1.095 & 1.010 & 1.16 \\
\hline 8 & 0.873 & 0.896 & 0.911 & 0.924 & 0.946 & 0.966 \\
\hline 9 & 0.783 & 0.789 & 0.812 & 0.853 & 0.876 & 0.898 \\
\hline 10 & 1.005 & 1.009 & 1.010 & 1.014 & 1.019 & 1.026 \\
\hline 11 & 0.720 & 0.744 & 0.763 & 0.788 & 0.793 & 0.814 \\
\hline 12 & 0.981 & 0.990 & 1.002 & 1.008 & 1.012 & 1.016 \\
\hline 13 & 1.0241 & 1.0246 & 1.0256 & 1.026 & 1.0278 & 1.0284 \\
\hline 14 & 0.945 & 0.956 & 0.963 & 0.978 & 0.998 & 1.006 \\
\hline 15 & 1.116 & 1.119 & 1.126 & 1.162 & 1.172 & 1.178 \\
\hline 16 & 0.90 & 0.96 & 0.99 & 1.003 & 1.009 & 1.014 \\
\hline 17 & 0.850 & 0.873 & 0.894 & 0.915 & 0.944 & 0.952 \\
\hline 18 & 1.045 & 1.056 & 1.066 & 1.076 & 1.084 & 1.088 \\
\hline 19 & 0.951 & 0.959 & 0.964 & 0.971 & 0.988 & 0.996 \\
\hline 20 & 1.011 & 1.017 & 1.022 & 1.032 & 1.046 & 1.066 \\
\hline 21 & 1.090 & 1.099 & 1.102 & 1.108 & 1.113 & 1.118 \\
\hline 22 & 0.751 & 0.764 & 0.773 & 0.781 & 0.791 & 0.886 \\
\hline 23 & 1.0486 & 1.0493 & 1.0498 & 1.051 & 1.056 & 1.076 \\
\hline 24 & 0.815 & 0.821 & 0.843 & 0.859 & 0.871 & 0.896 \\
\hline 25 & 0.915 & 0.919 & 0.926 & 0.953 & 0.962 & 0.978 \\
\hline 26 & 1.148 & 1.153 & 1.169 & 1.186 & 1.194 & 1.198 \\
\hline 27 & 1.0149 & 1.0164 & 1.0176 & 1.0188 & 1.0192 & 1.0198 \\
\hline 28 & 0.981 & 0.986 & 0.991 & 0.996 & 1.001 & 1.006 \\
\hline 29 & 0.990 & 0.996 & 1.003 & 1.006 & 1.014 & 1.018 \\
\hline 30 & 0.978 & 0.982 & 0.986 & 0.992 & 0.996 & 0.999 \\
\hline 31 & 1.0795 & 1.0799 & 1.0810 & 1.0826 & 1.0831 & 0.846 \\
\hline 32 & 0.768 & 0.769 & 0.774 & 0.782 & 0.794 & 0.85 \\
\hline
\end{tabular}

Table 11 Confirmatory experiment optimal process parameters' values

\begin{tabular}{ll}
\hline Process parameter & Optimal value \\
\hline$A$ & $140{ }^{\circ} \mathrm{C}$ \\
$B$ & $176^{\circ} \mathrm{C}$ \\
$C$ & $166^{\circ} \mathrm{C}$ \\
$D$ & $8 \mathrm{RPM}$ \\
$E$ & $129^{\circ} \mathrm{C}$ \\
\hline
\end{tabular}

Further investigations are made to these three factors by increasing the levels of each factor from two to five and the same procedure is repeated by taking modified orthogonal array. The pushing zone temperature, dimmer speed, die head temperature in the extrusion process again correlated significantly to the quality characteristic. This research concentrated on parameter design developed by Dr. Taguchi to calculate the $S / N$ ratio. After all the quality values were converted to $S / N$ ratios, the consequent analysis was conducted using the statistic estimation to estimate $S / N$ ratios under different parameter-level combinations. The highest value of $S / N$ ratio was conformed to be the optimum parameter-level combination, because it had the minimum variance. After Taguchi's S/ $N$ analysis and the following experiments, the combination of $A_{4}, B_{5}$ and $C_{2}$ was chosen as the optimum factor level which was as follows: pushing zone temperature $166^{\circ} \mathrm{C}$, dimmer speed $08 \mathrm{rpm}$, and die head temperature $192{ }^{\circ} \mathrm{C}$.

After the optimal combination of factor level was selected, the final process was to conduct the confirmation 
Table 12 The effects of controllable factors on withstanding pressure (WSP)signal to noise $(S / N)$ ratio

\begin{tabular}{llllr}
\hline Trial & $A$ & $B$ & $C$ & WSP-S/N \\
\hline 1 & 1 & 1 & 1 & -3.517 \\
2 & 1 & 3 & 1 & -1.947 \\
3 & 1 & 1 & 3 & -4.006 \\
4 & 1 & 3 & 3 & -0.969 \\
5 & 2 & 4 & 5 & -0.117 \\
6 & 2 & 2 & 4 & -2.238 \\
7 & 2 & 5 & 2 & 1.931 \\
8 & 2 & 2 & 2 & -1.715 \\
9 & 3 & 1 & 1 & -3.680 \\
10 & 3 & 3 & 1 & 0.273 \\
11 & 3 & 1 & 3 & -5.270 \\
12 & 3 & 3 & 3 & 0.025 \\
13 & 4 & 4 & 4 & 0.516 \\
14 & 4 & 2 & 5 & -0.535 \\
15 & 4 & 5 & 2 & 2.700 \\
16 & 4 & 2 & 2 & -0.470 \\
17 & 5 & 2 & 2 & -2.050 \\
18 & 5 & 4 & 2 & 1.330 \\
19 & 5 & 2 & 4 & -0.586 \\
20 & 5 & 5 & 5 & 0.626 \\
21 & 3 & 3 & 3 & 1.990 \\
22 & 3 & 1 & 3 & -4.770 \\
23 & 3 & 3 & 1 & 1.070 \\
24 & 3 & 1 & 1 & -3.260 \\
25 & 2 & 2 & 2 & -1.210 \\
26 & 2 & 4 & 2 & 3.211 \\
27 & 2 & 2 & 5 & 0.350 \\
28 & 2 & 5 & 4 & -0.130 \\
29 & 1 & 3 & 3 & 0.087 \\
30 & 1 & 1 & 3 & -0.226 \\
31 & 1 & 3 & 1 & 1.572 \\
32 & 1 & 1 & 1 & -4.760 \\
\hline & & & &
\end{tabular}

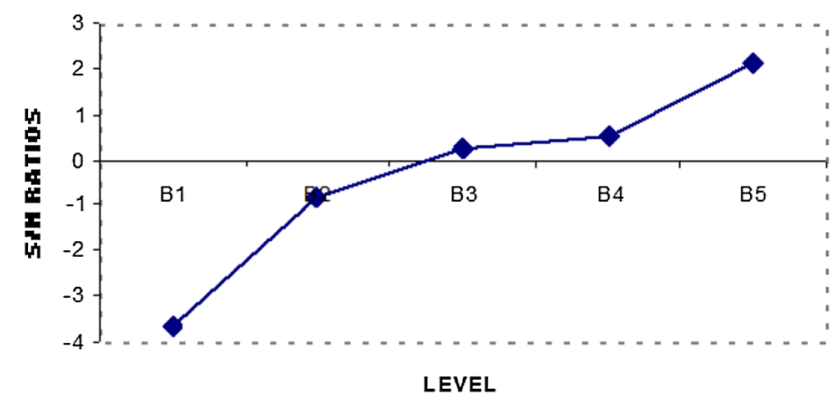

Fig. $8 S / N$ ratio graph 2

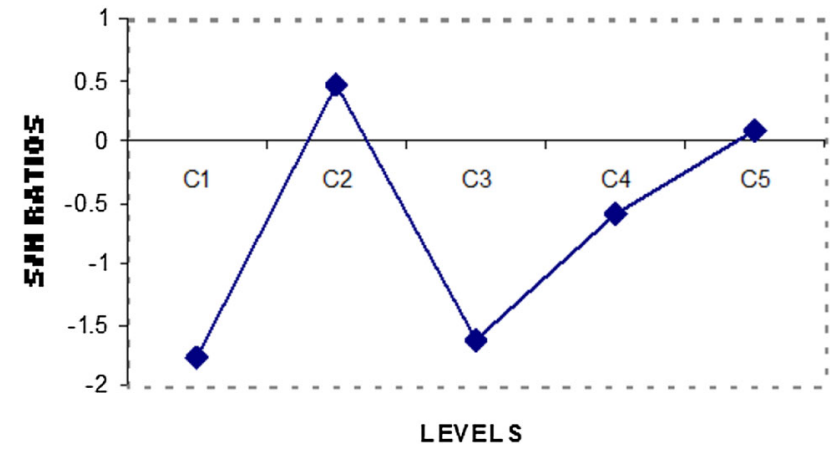

Fig. $9 S / N$ ratio graph 3

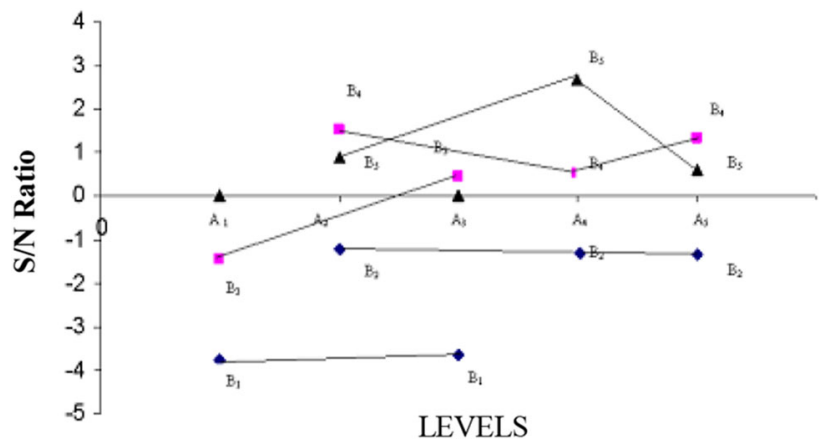

Fig. $10 S / N$ ratio graph 4

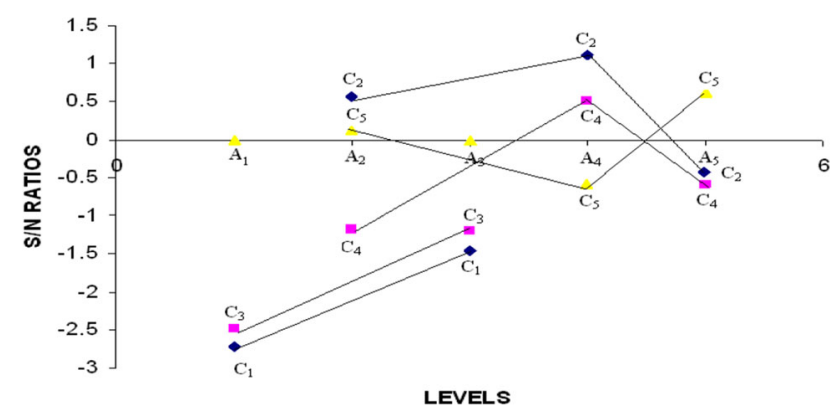

Fig. $11 S / N$ ratio graph 5

Fig. $7 S / N$ ratio graph 1 
Table 13 Confirmatory experiment results

\begin{tabular}{ll}
\hline Trial no. & Pressure values, MPa \\
\hline 1 & 0.9972 \\
2 & 1.0113 \\
3 & 1.009 \\
4 & 0.9985 \\
5 & 1.004 \\
\hline
\end{tabular}

run. The result successfully confirmed that the response value showed significant improvement from 0.60 to $1.004 \mathrm{MPa}$.

Open Access This article is distributed under the terms of the Creative Commons Attribution 4.0 International License (http://crea tivecommons.org/licenses/by/4.0/), which permits unrestricted use, distribution, and reproduction in any medium, provided you give appropriate credit to the original author(s) and the source, provide a link to the Creative Commons license, and indicate if changes were made.

\section{References}

Chen JC, Li Y, Cox RA (2009) Taguchi-based Six Sigma approach to optimize plasma cutting process: an industrial case study. Int $\mathbf{J}$ Adv Manuf Technol, Springer-Verlag London Limited 41: 760-769

Chen WL, Huang CY, Huang CY (2013) Finding efficient frontier of process parameters for plastic injection molding. J Ind Eng Int 9:25

Kamaruddin S, Khan ZA, Foong SH (2010) Application of Taguchi method in the optimization of injection moulding parameters for manufacturing products from plastic blend. IACSIT Int J Eng Technol 2(6):574-580 (ISSN:1793-8236)

Kim HR, Lee KY (2009) Application of Taguchi method to determine hybrid welding conditions of aluminum alloy. J Sci Ind Res 68:296-300
Lakshminarayanan AK, Balasubramanian V (2008) Process parameters optimization for friction stir welding of RDE-40 aluminium alloy using Taguchi technique. Trans Nonferr Metals Soc China, Science Direct, Science Press 18: 548-554

Lal SK, Vasudevan H (2013) Optimization of injection moulding process parameters in the moulding of low density polyethylene (LDPE). Int J Eng Res Dev 7(5): 35-39. www.ijerd.com (eISSN: 2278-067X, p-ISSN: 2278-800X)

Mariajayaprakash A, Senthilvelan T, Vivekananthan KP (2013) Optimisation of shock absorber process parameters using failure mode and effect analysis and genetic algorithm. J Ind Eng Int 9:18

Mehat NM, Kamaruddin S, Othman AR (2012) Reducing the shrinkage in plastic injection moulded gear via grey-basedTaguchi optimization method. Proceedings of the World Congress on Engineering 2012 vol III WCE 2012, 4-6 July 2012, London, UK [ISBN: 978-988-19252-2-0; ISSN: 2078-0958 (Print); ISSN: 2078-0966 (Online)]

Parameswara Rao CVS, Sarcar MMM (2009) Evaluation of optimal parameters for machining brass with wire cut EDM. J Sci Ind Res 68:32-35

Pareek R, Bhamniya J (2013) Optimization of injection moulding process using Taguchi and ANOVA. Int J Sci Eng Res 4(1):1-6 (ISSN 2229-5518)

Prashantha K, Soulestin J, Lacrampe MF, Lafranche E, Krawczak P, Dupin G, Claes M (2009) Taguchi analysis of shrinkage and warpage of injection-moulded polypropylene/multiwall carbon nanotubes nanocomposites. Express Polym Lett 3(10):630-638. doi:10.3144/expresspolymlett.2009.79

Sharma GVSS, Srinivasa Rao P (2013) Process capability improvement of an engine connecting rod machining process. J Ind Eng Int 9:37

Yu JC, Chen XX, Hung TR, Thibault F (2004) Optimization of extrusion blow molding processes using soft computing and Taguchi's method. J Intell Manuf 15:625-634. doi:10.1023/B: JIMS.0000037712.33636.41

Zaharudin AM, Talib RJ, Berhan MN, Budin S, Aziurah MS (2012) Taguchi method for optimizing the manufacturing parameters of friction materials. Int J Mech Mater Eng (IJMME) 7(1):83-88 